\title{
Microarchitecture and Nanomechanical Properties of Trabecular Bone After Strontium Administration in Osteoporotic Goats
}

\author{
Zhaoyang Li • Songlin Peng $\cdot$ Haobo Pan $\cdot$ Bin Tang $•$ \\ Raymond W. M. Lam • William W. Lu
}

Received: 10 April 2011 / Accepted: 19 July 2011 /Published online: 4 August 2011

(C) The Author(s) 2011. This article is published with open access at Springerlink.com

\begin{abstract}
Strontium (Sr) ralenate is a new agent used for the prevention and treatment of osteoporosis. As a boneseeking element, $98 \%$ of $\mathrm{Sr}$ is deposited in the bone and teeth after oral ingestion. However, the effect of $\mathrm{Sr}$ treatment on bone microarchitecture and bone nanomechanical properties remains unclear. In this study, 18 osteoporotic goats were divided into four groups according to the treatment regimen: control, calcium alone $(\mathrm{Ca})$, calcium and $\mathrm{Sr}$ at $24 \mathrm{mg} / \mathrm{kg}(\mathrm{Ca}+24 \mathrm{Sr})$, and calcium and $\mathrm{Sr}$ at $40 \mathrm{mg} / \mathrm{kg}(\mathrm{Ca}+40 \mathrm{Sr})$. The effects of $\mathrm{Sr}$ administration on bone microarchitecture and nanomechanical properties of trabecular bones were analyzed with micro-CT and nanoindentation test, respectively. Serum Sr levels increased sixand tenfold in the $\mathrm{Ca}+24 \mathrm{Sr}$ and $\mathrm{Ca}+40 \mathrm{Sr}$ groups, respectively. Similarly, $\mathrm{Sr}$ in the bone increased four- and sixfold in these two groups. Sr administration significantly increased trabecular bone volume fraction, trabecular thickness, and double-labeled new bone area. Sr administration, however, did not significantly change the nanomechanical properties of trabecular bone (elastic modulus and hardness). The data suggested that $\mathrm{Sr}$ administration
\end{abstract}

\footnotetext{
Z. Li $\cdot$ S. Peng $\cdot$ H. Pan $\cdot$ R. W. M. Lam $\cdot$ W. W. Lu

Department of Orthopaedics and Traumatology,

The University of Hong Kong,

Pokfulam, Hong Kong, China

B. Tang

Department of Mechanical Engineering,

The University of Hong Kong,

Pokfulam, Hong Kong, China

W. W. Lu ( $\square)$

Department of Orthopaedics and Traumatology,

The University of Hong Kong,

Room 907, Lab Block, 21 Sassoon Road,

Hong Kong, China

e-mail: wwlu@hku.hk
}

increased trabecular bone volume and improved the microarchitecture while maintaining the intrinsic tissue properties in the osteoporotic goat model.

Keywords Bone strength · Nanoindentation .

Osteoporosis · Ovariectomized goats $\cdot$ Strontium

\section{Introduction}

Osteoporosis is characterized by impaired bone quality which leads to decreased bone strength and increased susceptibility to fractures. Strontium (Sr)-containing compounds have been reported to exert anabolic effects on the skeleton when orally administered to animals $[1,2]$ and postmenopausal women [3-5]. Treatment with these agents increases bone mineral content and density, particularly at skeletal sites that are rich in trabecular bone, such as the lumbar spine $[2,3,6,7]$. In humans, studies on the mechanical properties of bone responsible for the anabolic action of $\mathrm{Sr}$ is mainly achieved by evaluation of fracture risks [3-5]. Human studies are limited by the difficulty in obtaining consistent specimens suitable for rigorous examination. So far, information on the microarchitecture and nanomechanical properties in response to $\mathrm{Sr}$ treatment in large osteoporosis animal models is lacking.

Nanoindentation has been proven to be a powerful tool for the measurement of local mechanical properties and is a fairly mature technique for measurements in biological tissues of the intrinsic material mechanical properties. This method circumvents common limitations that arise when applying large-scale mechanical testing techniques to biological tissues [8-10]. With the help of nanoindentation, measurement of localized changes due to enhanced or inhibited bone mineralization and remodeling becomes 
feasible. In recent years, micro-computerized tomography $(\mu \mathrm{CT})$ has been used to measure 3D bone structure of animals due to its relative ease in sample preparation, its noninvasive nature, and the high spatial resolution as compared with conventional histology [11]. Studies have demonstrated that $\mu \mathrm{CT}$ analysis of change patterns in $3 \mathrm{D}$ bone parameters may serve as a valuable tool for the evaluation of both anti-resorptive and anabolic agents in ovariectomized (OVX) animals [12].

Low dosage of $\mathrm{Sr}$ was employed in this study as $\mathrm{Sr}$ at high dosage may have deleterious effects on the bone [13-16]. For instance, Sr at high dosage may induce rickets, a disease characterized by the softening of bone, due simply to high levels of this element in soil, together with the possible contributions from the lack of sunshine and $\mathrm{Ca}$ dietary deficiency $[17,18]$. Since the main target populations for $\mathrm{Sr}$ treatment are postmenopausal osteoporotic women who are also susceptible to reduced renal function, the risk for osteomalacia should be considered. $\mathrm{Ca}$ and $\mathrm{P}$ supplements are added into the treatment regimen of $\mathrm{Sr}$ as the efficient absorption of these two elements plays an essential role in any increase in bone mass by forming osteoid and hydroxyapatite, which compose the bulk of bones [19, 20].

In a previous study, we reported that $\mathrm{Sr}-\mathrm{Ca}$ coadministration stimulated new bone formation as assessed by histomorphometry and molecular analysis of gene expressions [21]. In this work, we aimed to evaluate bone microarchitecture and nanomechanics at the lumbar spine of skeletally mature OVX goats after $\mathrm{Sr}-\mathrm{Ca}$ co-administration for 16 weeks. The trabecular microarchitectural parameters were quantified from $\mu \mathrm{CT}$, while the nanomechanical properties of single trabecula were determined by nanoindentation tests.

\section{Materials and Methods}

Animals

Eighteen goats with a mean age of 6.9 years (range, $6-8$ years) were ovariectomized by surgical procedures approved by the local ethics committee to induce osteoporosis 1 year before the evaluation was initiated. The mean weight of the goats was $37.5 \mathrm{~kg}$ (range, $35-43 \mathrm{~kg}$ ). The animals were then randomly assigned into four groups: (1) the control group $(n=3),(2)$ the Ca group ( $n=5),(3)$ the $\mathrm{Ca}+24 \mathrm{Sr}$ group $(n=5)$, and (4) the $\mathrm{Ca}+40 \mathrm{Sr}$ group $(n=5)$. All goats were fed with Rumilab Diet 5508 (Purina Mills, Richmond, IN, USA). Animals in the control group were fed with the above feed with low calcium. For animals in the treated groups, tricalcium phosphate (TCP) and Sr-fortified tricalcium phosphate (SrTCP) powder, synthesized by partially substituting $\mathrm{Ca}$ in TCP with Sr, were supplied in the feed and administered daily for 16 weeks. For animals in the $\mathrm{Ca}$ alone group, $\mathrm{Ca}$ phosphate was supplied in the feed at the elemental dosage of $100 \mathrm{mg} \mathrm{kg}^{-1}$ day $^{-1}$. In addition to Ca supplementation, $\mathrm{Sr}$ phosphate was supplied at 24 and $40 \mathrm{mg} \mathrm{kg}^{-1}$ day $^{-1}$ to the $\mathrm{Ca}+24 \mathrm{Sr}$ and $\mathrm{Ca}+40 \mathrm{Sr}$ groups, respectively. The detailed treatment dosages are listed in Table 1. At 14 and 3 days before killing, each animal was injected with $20 \mathrm{mg} / \mathrm{kg}$ tetracycline (Terramycin, Pfizer) to obtain a double fluorescent label at the site of active bone formation. All animals were killed at week 16 from the onset of treatment.

\section{Serum Biochemistry}

Blood samples were collected for $\mathrm{Sr}$ and $\mathrm{Ca}$ serum analysis by aortic puncture right before killing. The serum samples were prepared by acid digestion and the concentrations determined by applying inductively coupled plasma-atomic emission spectrometry (ICP-AES; iCAP 6300, Thermo Jarrell Ash Co., USA).

\section{Bone Mineral Content}

The bone mineral content was measured in bone blocks taken from the lumbar vertebrae (L2). The blocks were washed with distilled water before dehydrated at $100^{\circ} \mathrm{C}$ for $24 \mathrm{~h}$ in an oven and calcinated at $600^{\circ} \mathrm{C}$ for $20 \mathrm{~h}$. After calcination, the bone ashes were then dissolved in $6 \mathrm{~N} \mathrm{HCl}$. The $\mathrm{Ca}$ and $\mathrm{Sr}$ contents of the ashes were then determined by ICP-AES (iCAP 6300, Thermo Jarrell Ash Co.).

\section{Bone Specimen Preparation}

Lumbar vertebrae (L1-L4) were harvested from the fresh goat cadaver and freed of soft tissues. L3 was fixed in Millonig's phosphate-buffered $10 \%$ formalin, $\mathrm{pH} 7.4$, at $4^{\circ} \mathrm{C}$. After $24 \mathrm{~h}$, transverse sections $(1-\mathrm{cm}$ thickness) were prepared from the middle of each L3 vertebral body and dehydrated successively in $70 \%$, $95 \%$, and $100 \%$ ethanol before cleaning in xylene. These undecalcified specimens were then embedded in poly(methylmethacrylate) (PMMA).

Table 1 Groups and dosages of the experimental design

\begin{tabular}{lccc}
\hline \multirow{2}{*}{ Groups } & \multicolumn{2}{c}{ Elemental dosages } & \multirow{2}{*}{ No. of goats } \\
\cline { 2 - 3 } & $\mathrm{Ca}(\mathrm{mg} / \mathrm{kg} /$ day $)$ & $\mathrm{Sr}(\mathrm{mg} / \mathrm{kg} / \mathrm{day})$ & \\
\hline Control & 0 & 0 & 3 \\
$\mathrm{Ca}$ & 100 & 0 & 5 \\
$\mathrm{Ca}+24 \mathrm{Sr}$ & 100 & 24 & 5 \\
$\mathrm{Ca}+40 \mathrm{Sr}$ & 100 & 40 & 5 \\
\hline
\end{tabular}


Specimen of L3 with PMMA embedding was processed with a high-speed, water-cooled diamond saw (EXAKT 300 CP Band System, Norderstedt, Germany) to give transverse sections of two different thicknesses: $3 \mathrm{~mm}$ and $40 \mu \mathrm{m}$. After being used for $\mu \mathrm{CT}$ test, the 3-mm-thick sections were polished by sand paper with increasing fineness from 240 to 1,200 grit and then further polished on a micro-cloth with 6-, 1-, and $0.05-\mu \mathrm{m}$ alumina suspension for $\mu \mathrm{CT}$ and the nanoindentation test. The 40- $\mu$ m-thick sections were polished (EXAKT $400 \mathrm{CS}$ Micro Grinding System, Norderstedt, Germany) and mounted for visualization by fluorescent microscopy (Nikon H600L Microscope System, Japan).

\section{New Bone Area Measurement}

To measure the new bone formation, the new bone area between the tetracycline labels in cancellous bone was determined. On the unstained $40-\mu \mathrm{m}$-thick sections, doublelabeled bone areas $\left(\mathrm{dL} . \mathrm{Ar}_{i}\right)$ were obtained and normalized to trabecula area (in percent, dL.Ar/Tb.Ar) under fluorescent microscopy (as shown in Fig. 1) on six representative fields per bone sample. The representative tissue percentage occupied by the double-labeled bone (dL.Ar/Tb.Ar) were computer-generated using the equation below:

$\mathrm{dL} . A r / \mathrm{Tb} . A r=\frac{\sum_{i=1}^{6} \mathrm{dL} \cdot A r_{i}}{\sum_{i=1}^{6} \mathrm{~Tb} \cdot A r_{i}}$

The measurement was $2 \mathrm{D}$, confined to the spongiosa, and made using a $\times 40$ objective lens. Image analyses were automatically performed with a program of Image Pro Plus 5.0 (Media Cybernetics, Inc. MD, USA).

\section{Micro-CT Scanning}

PMMA-embedded lumbar vertebrae (L3) were cut to give 3-mm midshaft cross-sections for $3 \mathrm{D}$ data and image acquisition using a desktop $\mu \mathrm{CT}$ system $(\mu \mathrm{CT}-40$; Scanco Medical, Bassersdorf, Switzerland). Micro-CT scans were performed on the entire 3-mm specimen to give 100 successive $30-\mu \mathrm{m}$ slices. Scanning was performed with the following parameters: $21-\mu \mathrm{m}$ isotropic voxel size, $55-\mathrm{keV}$ voltage, 109-mA current, 200-ms integration time, and 4,000 projections. Threedimensional information was obtained by stacking the measured slices on top of each other. After digital removal of the surrounding cortical bone, the entire spongiosa was used for subsequent morphometric analysis. A representative $3 \mathrm{D}$ visualization of a complete measurement is shown in Fig. 2. Bone volume fraction

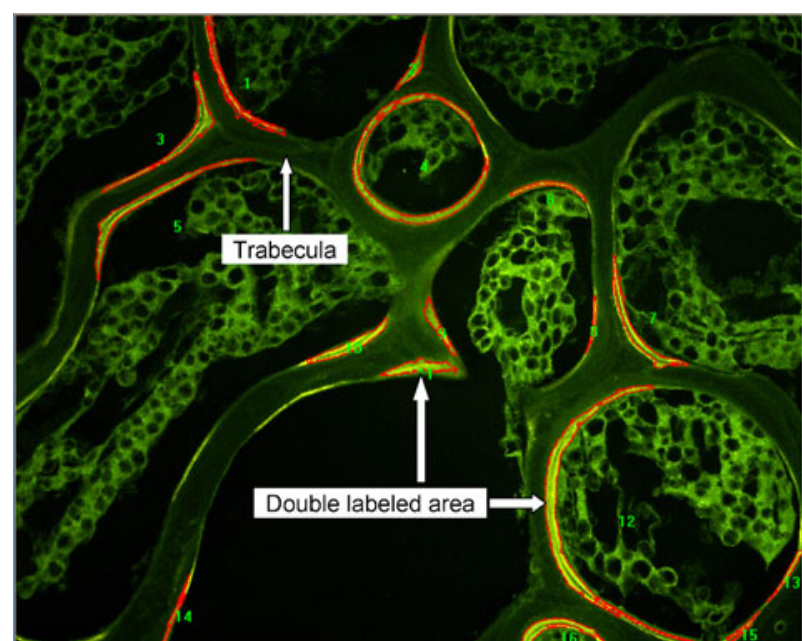

Fig. 1 Tetracycline double-labeled areas under fluorescent microscopy. Measurements of double-labeled surface area $\left(\mathrm{dL} . \mathrm{Ar}_{i}\right)$ of selected scope and the area of trabecular bone $\left(\mathrm{B} . \mathrm{Ar}_{i}\right)$ were performed on six representative fields for each sample. The result is given by percentage of double-labeled area to bone area (dL.Ar/B.Ar)

(bone volume/total volume (BV/TV)), trabecular thickness (Tb.Th), number (Tb.N), and separation (Tb.Sp) were also evaluated. The connectivity density (Conn.D) was calculated using the Euler method [22].

Nanoindentation Test and Data Analysis

After assessment with the $\mu \mathrm{CT}$ test, the 3-mm-thick sections were polished by sandpaper with increasing fineness (from 240 to 1,200 grit) and then further polished on a micro-cloth with 6-, 1-, and $0.05-\mu \mathrm{m}$ alumina suspension for the nanoindentation test. The test was performed using a nanoindenter equipped with a Beckovich tip (CSM Instruments SA, Switzerland). For ease of comparison, a typical load-hold scheme, with a peak load of $4 \mathrm{mN}$, loading rate $8 \mathrm{mN} / \mathrm{min}$, holding time $60 \mathrm{~s}$, and unloading rate $10 \mathrm{mN} / \mathrm{min}$, was used for all the nanoindentation tests in this study. Five different regions were selected for the nanoindentation tests to reduce random errors, as shown in Fig. 3a. In each region, five indents were made to calculate the elastic modulus and hardness of nanoindentation (Fig. 3b, c). With the nanoindentation technique, the most commonly used method for data analysis is the Oliver-Pharr method [23], which assumes that the tip-sample contact is purely elastic. Here, we employed a method developed by Ngan et al. [24, 25] that corrected for the viscoelastic effects during nanoindentation measurements.

\section{Statistical Analysis}

All data were expressed as the mean $\pm \mathrm{SD}$. The analysis was performed with one-way analysis of variance. A 
Fig. 2 Representative MicroCT 3D image of cross-sectional bone from the goat lumbar vertebral body (L3). The microarchitectures of the lumbar spine of goats in the four different groups are shown above

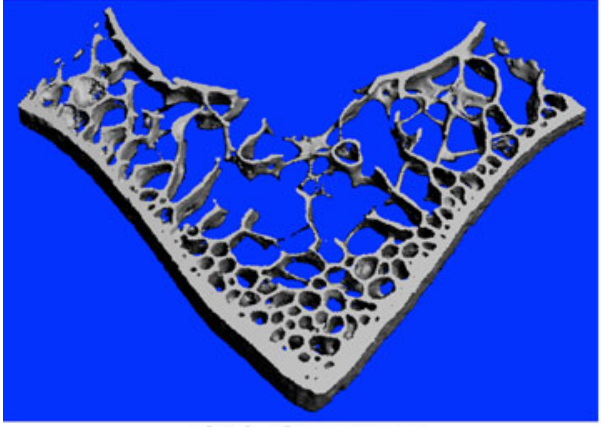

(A) Control

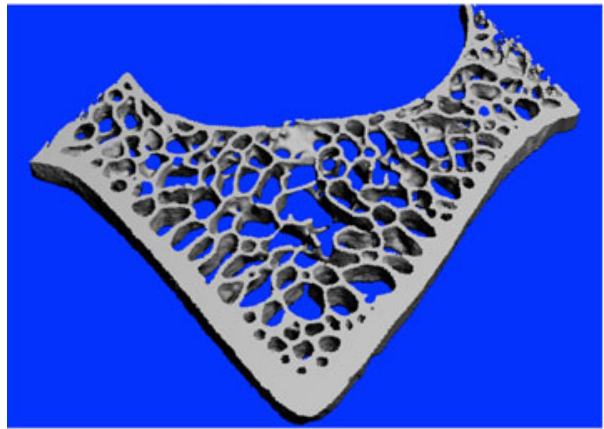

(C) $\mathrm{Ca}+24 \mathrm{Sr}$

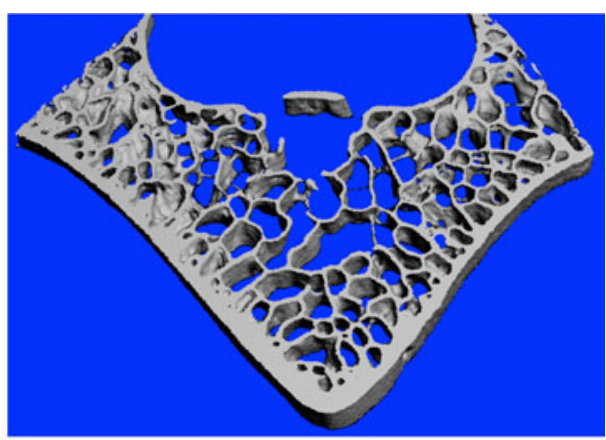

(B) $\mathrm{Ca}$

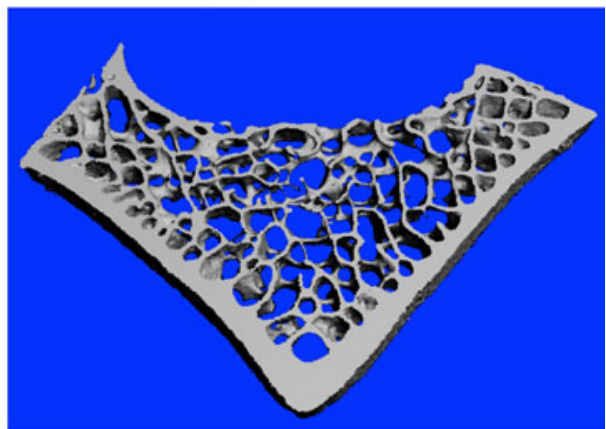

(D) $\mathrm{Ca}+40 \mathrm{Sr}$
Student-Neuman-Keuls post hoc test was conducted on the pooled data to determine the differences between the groups at a significance level of $p<0.05$.

\section{Results}

\section{Serum Biochemistry}

The Sr serum concentrations before and after treatments are shown in Fig. 4. No significant difference was observed between the control and treated groups prior to treatment. The mean serum Sr concentrations in the Ca group (2.44 $\left.0.31 \times 10^{-3} \mathrm{mmol} / \mathrm{l}\right)$ and control group $(3.34 \pm 0.12 \times$ $\left.10^{-3} \mathrm{mmol} / \mathrm{l}\right)$ were comparable. In contrast, the mean $\mathrm{Sr}$ concentration in the $\mathrm{Ca}+24 \mathrm{Sr}$ and $\mathrm{Ca}+40 \mathrm{Sr}$ groups increased considerably to $19.38 \pm 3.46 \times 10^{-3}$ and $35.28 \pm$ $7.88 \times 10^{-3} \mathrm{mmol} / \mathrm{l}$, respectively.

\section{Bone Mineral Content}

As shown in Fig. 5, the Ca group $(296 \pm 39 \mathrm{mg} / \mathrm{kg})$ had slightly decreased $\mathrm{Sr}$ concentrations in the lumbar vertebrae compared with the control group $(331 \pm 87 \mathrm{mg} / \mathrm{kg})$. The lumbar vertebrae $\mathrm{Sr}$ levels were increased to $1,133 \pm 341$ and $1,834 \pm 417 \mathrm{mg} / \mathrm{kg}$ in the $\mathrm{Ca}+24 \mathrm{Sr}$ and $\mathrm{Ca}+40 \mathrm{Sr}$ groups, respectively.
New Bone Area Measurement

In order to observe the anabolic effects of $\mathrm{Sr}$, tetracycline double-labeled areas (dL.Ar/B.Ar) were measured. In the control and $\mathrm{Ca}$ treatment groups, the dL.Ar/B.Ar were $3.49 \pm 1.01 \%$ and $3.61 \pm 0.98 \%$, respectively, and no significant difference was observed. However, the dL. Ar/B.Ar was significantly increased by $16.90 \% \quad(p=$ $0.043)$ and $32.33 \%(p=0.037)$ in the $\mathrm{Ca}+24 \mathrm{Sr}$ and $\mathrm{Ca}+$ $40 \mathrm{Sr}$ groups, respectively.

\section{Micro-CT Parameters of Lumbar Vertebral Body}

Table 2 summarizes the effects of all treatments on 3D bone microarchitecture parameters. Trabecular bone volume fraction (bone volume/tissue volume, BV/TV) was significantly greater in the $\mathrm{Ca}+24 \mathrm{Sr}$ group compared with both the control and $\mathrm{Ca}$ groups $(+12.22 \%$ and $+9.78 \%, p=0.010$ and 0.0432 , respectively). BV/TV was also significantly greater in the $\mathrm{Ca}+40 \mathrm{Sr}$ group compared with both the control and $\mathrm{Ca}$ groups $(+22.78 \%$ and $+20.11 \%, p=0.003$ and 0.012 , respectively). Tb.Th was significantly greater in both $\mathrm{Ca}+24 \mathrm{Sr}$ and $\mathrm{Ca}+40 \mathrm{Sr}$ groups compared with the control group $(+21.84 \%$ and $+32.76 \%, p=0.038$ and 0.015 , respectively). Meanwhile, $\mathrm{Tb}$. Th was significantly greater in both $\mathrm{Ca}+24 \mathrm{Sr}$ and $\mathrm{Ca}+40 \mathrm{Sr}$ groups compared with the Ca group $(+13.98 \%$ and $+24.19 \%, p=0.032$ and 0.028 , 
Fig. 3 Nanoindentation test performed on single trabecula of lumbar vertebra. a Nanoindentation test was performed at five different regions. b Indents were performed on the junction of trabeculae to prevent potential artifacts caused by intrinsic bone defects. For each region, six indents were performed, the larger one for marking (b) and the other five for data collection (c)
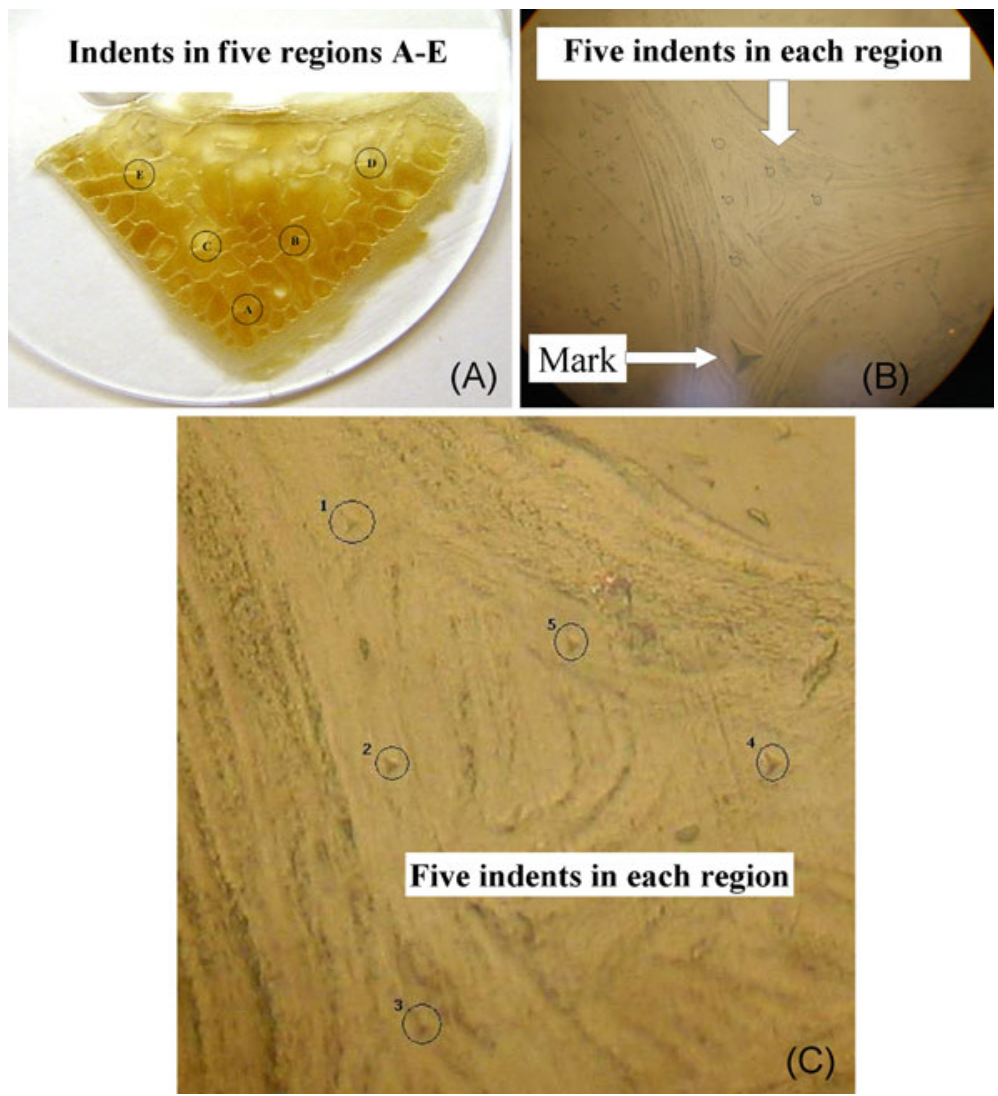

respectively). The decrease in Tb.N was accompanied with an increase in $\mathrm{Tb} . \mathrm{Sp}$ in response to treatment with $\mathrm{Ca}$ alone. In contrast, in response to $\mathrm{Sr}-\mathrm{Ca}$ treatment, $\mathrm{Tb} . \mathrm{N}$ increased while Tb.Sp decreased. The Conn.D was increased slightly in $\mathrm{Ca}$ alone, while it was significantly greater in the $\mathrm{Ca}+$ $24 \mathrm{Sr}$ and $\mathrm{Ca}+40 \mathrm{Sr}$ groups (35.46\% and 28.22\%, $p=0.029$ and 0.034 , respectively) compared with the control group.

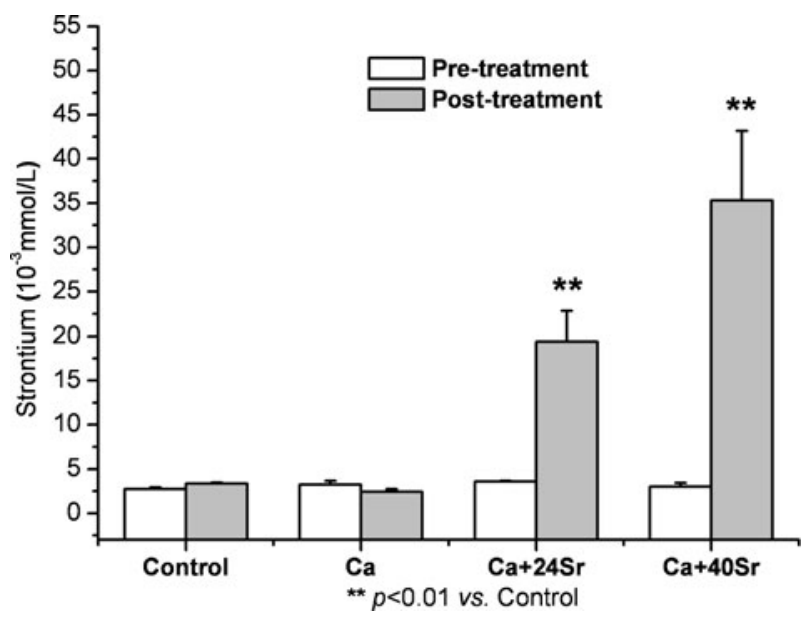

Fig. 4 Strontium serum concentrations pre- and post-treatments. No significant difference was observed between the control and treated groups prior to treatment. $\mathrm{Ca}$ alone treatment decreased $\mathrm{Sr}$ level marginally; in contrast, $\mathrm{Sr}$ concentrations increased considerably with $\mathrm{Ca}-\mathrm{Sr}$ co-administration

\section{Nanoindentation of Single Trabecula}

The elastic modulus $(E)$ and hardness $(H)$ of the single trabecula is shown in Table 3. The mean modulus of these four groups was comparable and no significant difference was observed. Although we observed a tendency for both $\mathrm{Ca}$ alone and $\mathrm{Ca}$ combined with $\mathrm{Sr}$ to increase the elastic

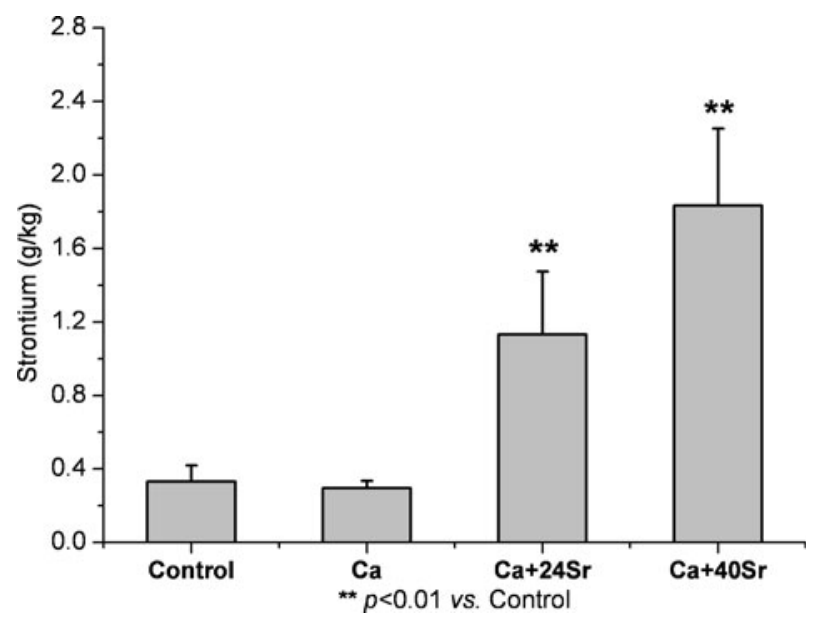

Fig. 5 Strontium concentration in lumbar vertebra. Sr concentration decreased slightly with $\mathrm{Ca}$ alone treatment; however, $\mathrm{Ca}-\mathrm{Sr}$ coadministration increased $\mathrm{Sr}$ levels significantly in both femur and lumbar vertebra 
Table 2 Microarchitecture parameters of lumbar vertebral body of goats in control and experimental groups

${ }^{*} p<0.05$ (vs. control group); $* * p<0.05$ (vs. Ca group)

\begin{tabular}{lllll}
\hline Parameter & \multicolumn{3}{l}{ Groups } & \\
\cline { 2 - 5 } & Control & $\mathrm{Ca}$ & $\mathrm{Ca}+24 \mathrm{Sr}$ & $\mathrm{Ca}+40 \mathrm{Sr}$ \\
\hline BV/TV & $0.180 \pm 0.006$ & $0.184 \pm 0.009$ & $0.202 \pm 0.013^{*, * *}$ & $0.221 \pm 0.017^{*, * *}$ \\
Tb.Th $(\mathrm{mm})$ & $0.174 \pm 0.016$ & $0.186 \pm 0.020$ & $0.212 \pm 0.025^{*, * *}$ & $0.231 \pm 0.031^{*, * *}$ \\
Tb.Sp $(\mathrm{mm})$ & $0.474 \pm 0.062$ & $0.519 \pm 0.135$ & $0.435 \pm 0.048$ & $0.432 \pm 0.045$ \\
Tb.N $(1 / \mathrm{mm})$ & $2.337 \pm 0.593$ & $2.123 \pm 0.656$ & $2.559 \pm 0.432$ & $2.618 \pm 0.530$ \\
Conn.D $\left(1 / \mathrm{mm}^{3}\right)$ & $3.154 \pm 0.791$ & $3.419 \pm 0.862$ & $3.789 \pm 1.010^{*}$ & $4.003 \pm 1.208^{*}$ \\
\hline
\end{tabular}

modulus to hardness ratio $(E / H)$, this effect was not found to be statistically significant. The $E / H$ increased by $0.86 \%$ $(p=0.746)$ in the $\mathrm{Ca}$-alone treatment group. In the $\mathrm{Ca}+24 \mathrm{Sr}$ and $\mathrm{Ca}+40 \mathrm{Sr}$ groups, the $E / H$ increased by $7.64 \%(p=$ $0.378)$ and $6.72 \%(p=0.122)$, respectively.

\section{Discussion}

The OVX goat is an acceptable animal model of osteoporosis that allows a detailed study of the effects of therapies at skeletal sites relevant to the treatment of osteoporosis $[26,27]$. In a previous study on OVX goats, we showed that $\mathrm{Sr}-\mathrm{Ca}$ co-administration significantly increased mineral apposition rate and the osteoblast-related gene expression (Runx2), demonstrating the anabolic effect of $\mathrm{Sr}-\mathrm{Ca}$ compound in the OVX goat model. However, it remains unknown whether the Sr-mediated anabolic effect leads to better trabecular bone microarchitecture and intrinsic bone tissue properties. Our data presented here showed that $\mathrm{Sr}-$ $\mathrm{Ca}$ co-administration significantly improved trabecular bone mass and microarchitecture while not altering the intrinsic bone tissue properties of trabecular bone.

The dosage of $\mathrm{Sr}$ treatment varied in a wide range in the animal studies. In a recent study on OVX rats, $\mathrm{Sr}$ at the dose of $25 \mathrm{mg} \mathrm{kg}^{-1}$ day $^{-1}$ failed to exert anabolic effect on the trabecular bone [28]. The effective dose of Sr treatment in the animals ranged from 100 to $1,024 \mathrm{mg} \mathrm{kg}^{-1}$ day $^{-1}$ [29-32]. The Sr dosages used in the present study were lower than that in the previous animal studies [29-32], but improved both static and dynamic bone histomorphometry parameters as assessed by micro-CT and bone histomorphometry, respectively. The higher bone volume is mainly due to higher trabecular thickness, as there was no significant change for trabecular number, suggesting that the main anabolic effect of $\mathrm{Sr}$ is to thicken the existing trabeculae instead of restoring trabecular number. To validate the anabolic effect of $\mathrm{Sr}$ on bone at the tissue level, we evaluated the dynamic bone formation parameter using double fluorescence labeling. The dynamic bone formation parameter such as the double-labeled new bone area was significantly higher in the $\mathrm{Sr}-\mathrm{Ca}$ compound group compared with the $\mathrm{Ca}$ or control groups. These data from the micro-CT and bone histomorphometry reflect that the activity of osteoblasts/progenitors in bones has increased after $\mathrm{Sr}-\mathrm{Ca}$ compound treatment.

Calcium supplementation alone did not change the serum or bone $\mathrm{Ca}$ levels, but did result in a marginally decreased serum and bone $\mathrm{Sr}$ concentrations. This may be due to the competitive effect between $\mathrm{Sr}$ and $\mathrm{Ca}$ which share similar physical and chemical properties. Furthermore, the bone mineral content assay indicated that Sr was taken up by the bone matrix in cancellous (lumbar vertebrae) bone in a dose-dependent manner. Even though Sr content significantly increased, the level of $\mathrm{Ca}$ was not considerably changed since the amount of $\mathrm{Ca}$ was much higher than the trace element $\mathrm{Sr}$.

Bone strength is determined not only by bone geometry, cortical bone thickness, porosity, and trabecular bone microarchitecture but also by the intrinsic bone tissue property. The effect of $\mathrm{Sr}$ treatment on bone mineral density, volume, and microarchitecture has been intensively investigated in a number of studies. Very little information on the effect of $\mathrm{Sr}$ on intrinsic bone tissue quality is available [1]. By the nanoindentation test, we demonstrated that there were no significant changes for both elastic modulus and hardness in trabecular bone in $\mathrm{Sr}$ treatment and $\mathrm{Ca}$ or control groups. These results are consistent with
Table 3 Elastic modulus $(E)$ and hardness $(H)$ of single trabecula

\begin{tabular}{lccc}
\hline Group & Elastic modulus, $E(\mathrm{GPa})$ & Hardness, $H(\mathrm{MPa})$ & $E / H$ \\
\hline Control & $14.025 \pm 0.017$ & $685.800 \pm 37.937$ & $20.790 \pm 0.707$ \\
$\mathrm{Ca}$ & $14.052 \pm 1.102$ & $670.146 \pm 62.170$ & $20.970 \pm 0.461$ \\
$\mathrm{Ca}+24 \mathrm{Sr}$ & $14.017 \pm 0.297$ & $639.959 \pm 63.869$ & $22.378 \pm 2.100$ \\
$\mathrm{Ca}+40 \mathrm{Sr}$ & $13.542 \pm 0.665$ & $642.025 \pm 28.620$ & $22.187 \pm 0.720$ \\
\hline
\end{tabular}


the recent report that showed no significant difference for elastic modulus between placebo and $\mathrm{Sr}$ ranelate group in postmenopausal women [33]. The condition for the samples (dry or wet) plays an essential role on the determination of effect of Sr treatment on elastic modulus or hardness. As in another study, significant effects of Sr treatment on the elastic modulus, hardness, and dissipated energy are only observed in the vertebrae samples in physiological (hydrated) but not in dry conditions [1]. The reason for the failure to observe the obvious effect of $\mathrm{Sr}$ treatment on intrinsic tissue quality at dry conditions remains unknown. One of the possible reasons is that in the bone mineral phase, $\mathrm{Sr}$ is mainly located in the hydrated layer and could potentially structurally modify the bone matrix in relation to the hydration state of the bony tissue.

In this study, hardness in all treatment groups was lower compared with the control group, and the differences were not statistically significant. Indentation hardness of the bone depends heavily on the degree of bone mineralization [34]. Under the influence of the anabolic effect of Sr, the slight decrease in bone hardness may result from the enhanced formation of a less mineralized new bone. $E / H$ is useful in the evaluation of the overall deformation characteristics during indentation and is proportional to the fracture toughness of the bone [35]. Higher $E / H$ values correspond to a more ductile material, while lower $E / H$ values generally indicate a more brittle material. Upon treatment with $\mathrm{Sr}$, a considerably higher $E / H$ ratio, without statistical significance, was observed.

The result of a large animal model will show more clinical relevance than that of rodents, but there are still some limitations in the current study, such as the relatively small sample size compared with small animal studies. Increasing the sample size in each group may provide more valuable statistical representation for the data. The hardness and modulus of a single trabecula were determined in dehydrated sample, which was different from physiological conditions. Obviously, more work has to be conducted on fresh samples to guarantee the elucidation of the $\mathrm{Sr}$ treatment on the nanomechanical properties of bone.

In conclusion, our findings showed that $\mathrm{Sr}$ treatment stimulated new bone formation and also improved bone microstructure in osteoporotic goats as measured by $\mu \mathrm{CT}$. $\mathrm{Sr}$ treatment significantly increased trabecular bone volume primarily by increasing trabecular thickness, but the nanomechanical properties of a single trabecula were not altered. The results suggested that the reduced osteoporotic fracture risk was mainly due to the improvement in bone microarchitecture instead of the intrinsic tissue properties of a single bone unit.

Acknowledgments This study was partially supported by the Hong Kong RGC (HKU 7147/07E) and Hong Kong ITF Fund (GHP/009/
06). The authors would like to thank Mr. Stephen Chan and Patrick Wong for their expert technical assistance in specimen preparation.

Open Access This article is distributed under the terms of the Creative Commons Attribution Noncommercial License which permits any noncommercial use, distribution, and reproduction in any medium, provided the original author(s) and source are credited.

\section{References}

1. Ammann P, Badoud I, Barraud S, Dayer R, Rizzoli R (2007) Strontium ranelate treatment improves trabecular and cortical intrinsic bone tissue quality, a determinant of bone strength. J Bone Miner Res 22:1419-1425

2. Ammann P, Shen V, Robin B, Mauras Y, Bonjour JP, Rizzoli R (2004) Strontium ranelate improves bone resistance by increasing bone mass and improving architecture in intact female rats. J Bone Miner Res 19:2012-2020

3. Meunier PJ, Roux C, Seeman E, Ortolani S, Badurski JE, Spector TD, Cannata J, Balogh A, Lemmel EM, Pors-Nielsen S (2004) The effects of strontium ranelate on the risk of vertebral fracture in women with postmenopausal osteoporosis. N Engl J Med 350:459-468

4. Roux C, Reginster JY, Fechtenbaum J, Kolta S, Sawicki A, Tulassay Z, Luisetto G, Padrino JM, Doyle D, Prince R (2006) Vertebral fracture risk reduction with strontium ranelate in women with postmenopausal osteoporosis is independent of baseline risk factors. J Bone Miner Res 21:536-542

5. Seeman E, Vellas B, Benhamou C, Aquino JP, Semler J, Kaufman JM, Hoszowski K, Varela AR, Fiore C, Brixen K (2006) Strontium ranelate reduces the risk of vertebral and nonvertebral fractures in women eighty years of age and older. J Bone Miner Res 21:1113-1120

6. Shahnazari M, Lang DH, Fosmire GJ, Sharkey NA, Mitchell AD, Leach RM (2007) Strontium administration in young chickens improves bone volume and architecture but does not enhance bone structural and material strength. Calcif Tissue Int 80:160-166

7. Shahnazari M, Sharkey NA, Fosmire GJ, Leach RM (2006) Effects of strontium on bone strength, density, volume, and microarchitecture in laying hens. J Bone Miner Res 21:1696-1703

8. Hoffler CE, Moore KE, Kozloff K, Zysset PK, Brown MB, Goldstein SA (2000) Heterogeneity of bone lamellar-level elastic moduli. Bone 26:603-609

9. Hengsberger S, Ammann P, Legros B, Rizzoli R, Zysset P (2005) Intrinsic bone tissue properties in adult rat vertebrae: modulation by dietary protein. Bone $36: 134-141$

10. Mittra E, Akella S, Qin YX (2006) The effects of embedding material, loading rate and magnitude, and penetration depth in nanoindentation of trabecular bone. J Biomed Mater Res A 79:8693

11. Barou O, Valentin D, Vico L, Tirode C, Barbier A, Alexandre C, Lafage-Proust MH (2002) High-resolution three-dimensional micro-computed tomography detects bone loss and changes in trabecular architecture early: comparison with DEXA and bone histomorphometry in a rat model of disuse osteoporosis. Invest Radiol 37:40-46

12. Xiang A, Kanematsu M, Mitamura M, Kikkawa H, Asano S, Kinoshita M (2006) Analysis of change patterns of microcomputed tomography 3-dimensional bone parameters as a highthroughput tool to evaluate antiosteoporotic effects of agents at an early stage of ovariectomy-induced osteoporosis in mice. Invest Radiol 41:704-712

13. Oste L, Bervoets AR, Behets GJ, Dams G, Marijnissen RL, Geryl H, Lamberts LV, Verberckmoes SC, Van Hoof VO, De Broe ME 
(2005) Time-evolution and reversibility of strontium-induced osteomalacia in chronic renal failure rats. Kidney Int 67:920-930

14. Schrooten I, Behets GJ, Cabrera WE, Vercauteren SR, Lamberts LV, Verberckmoes SC, Bervoets AJ, Dams G, Goodman WG, De Broe ME (2003) Dose-dependent effects of strontium on bone of chronic renal failure rats. Kidney Int 63:927-935

15. D'Haese PC, Schrooten I, Goodman WG, Cabrera WE, Lamberts LV, Elseviers MM, Couttenye MM, De Broe ME (2000) Increased bone strontium levels in hemodialysis patients with osteomalacia. Kidney Int 57:1107-1114

16. Schrooten I, Elseviers MM, Lamberts LV, De Broe ME, D'Haese PC (1999) Increased serum strontium levels in dialysis patients: an epidemiological survey. Kidney Int 56:1886-1892

17. Grynpas MD, Marie PJ (1990) Effects of low doses of strontium on bone quality and quantity in rats. Bone 11:313-319

18. Omdahl JL, DeLuca HF (1971) Strontium induced rickets: metabolic basis. Science 174:949-951

19. Heaney RP, Nordin BE (2002) Calcium effects on phosphorus absorption: implications for the prevention and co-therapy of osteoporosis. J Am Coll Nutr 21:239-244

20. Shiraishi A, Ito M, Hayakawa N, Kubota N, Kubodera N, Ogata E (2006) Calcium supplementation does not reproduce the pharmacological efficacy of alfacalcidol for the treatment of osteoporosis in rats. Calcif Tissue Int 78:152-161

21. Li Z, Lu WW, Chiu PK, Lam RW, Xu B, Cheung KM, Leong JC, Luk KD (2009) Strontium-calcium coadministration stimulates bone matrix osteogenic factor expression and new bone formation in a large animal model. J Orthop Res 27:758-762

22. Hildebrand T, Ruegsegger P (1997) Quantification of bone microarchitecture with the structure model index. Comput Methods Biomech Biomed Eng 1:15-23

23. Oliver WC, Pharr GM (1992) An improved technique for determining hardness and elastic modulus using load and displacement sensing indentation experiments. J Mater Res 7:1546-1583

24. Ngan AHW, Wang HT, Tang B, Sze KY (2005) Correcting powerlaw viscoelastic effects in elastic modulus. Measurement using depth-sensing indentation. International J Solids Structures 42:1831-1846
25. Tang B, Ngan AHW, Lu WW (2006) Viscoelastic effects during depth-sensing indentation of cortical bone tissues. Philos Mag 86:5653-5666

26. Leung KS, Siu WS, Cheung NM, Lui PY, Chow DH, James A, Qin L (2001) Goats as an osteopenic animal model. J Bone Miner Res 16:2348-2355

27. Siu WS, Cheung NM, Lui PPY, Chow DHK, James A, Qin L, Leung KS (2001) Establishment of an osteoporotic goat animal model. Bone 28:532

28. Fuchs RK, Allen MR, Condon KW, Reinwald S, Miller LM, McClenathan D, Keck B, Phipps RJ, Burr DB (2008) Strontium ranelate does not stimulate bone formation in ovariectomized rats. Osteoporos Int 19:1331-1341

29. Buehler J, Chappuis P, Saffar JL, Tsouderos Y, Vignery A (2001) Strontium ranelate inhibits bone resorption while maintaining bone formation in alveolar bone in monkeys (Macaca fascicularis). Bone 29:176-179

30. Hott M, Deloffre P, Tsouderos Y, Marie PJ (2003) S12911-2 reduces bone loss induced by short-term immobilization in rats. Bone 33:115-123

31. Boivin G, Deloffre P, Perrat B, Panczer G, Boudeulle M, Mauras Y, Allain P, Tsouderos Y, Meunier PJ (1996) Strontium distribution and interactions with bone mineral in monkey iliac bone after strontium salt (S 12911) administration. J Bone Miner Res 11:1302-1311

32. Grynpas MD, Hamilton E, Cheung R, Tsouderos Y, Deloffre P, Hott M, Marie PJ (1996) Strontium increases vertebral bone volume in rats at a low dose that does not induce detectable mineralization defect. Bone 18:253-259

33. Roschger P, Manjubala I, Zoeger N, Meirer F, Simon R, Li C, Fratzl-Zelman N, Misof BM, Paschalis EP, Streli C, Fratzl P, Klaushofer K (2010) Bone material quality in transiliac bone biopsies of postmenopausal osteoporotic women after 3 years of strontium ranelate treatment. J Bone Miner Res 25:891-900

34. van Ruijven LJ, Mulder L, van Eijden TM (2007) Variations in mineralization affect the stress and strain distributions in cortical and trabecular bone. J Biomech 40:1211-1218

35. Fan Z, Smith PA, Eckstein EC, Harris GF (2006) Mechanical properties of OI type III bone tissue measured by nanoindentation. J Biomed Mater Res A 79:71-77 